\title{
Cannabis, Lord Shiva and Holy Men: Cannabis Use Among Sadhus in Nepal
}

\author{
Acharya SL ${ }^{1}$, Howard J2 ${ }^{\text {, Pant SB }}{ }^{3}$, Mahatma SS ${ }^{4}$, Copeland J ${ }^{5}$
}

\begin{abstract}
1. Ministry of Health and Population, Nepal CCM, Nepal, 2. National Drug and Alcohol Research Centre, UNSW Australia, 3. Department of Psychiatry and Mental Health, Tribuvan University Teaching Hospital and Saarathi OST Program, Nepal, 4. Ram Mandir, Pashupathinath Temple, Kathmandu, Nepal, 5. National Cannabis Prevention and Information Centre, UNSW Australia
\end{abstract}

E-mail *Corresponding author:jphoward.work@gmail.com

\begin{abstract}
Background: Despite being illegal in Nepal, cannabis grows wild, is cultivated, readily available and often consumed during religious festivals, such as those in honour of the Hindu god Shiva. Holy men (sadhus) also consume cannabis to aid meditation, and many are believed to suggest that as a substance favoured by Lord Shiva, and, as such, should be used. However, there are concerns that all cannabis use in Nepal is not benign, and that there are negative health and social consequences from its use for some consumers. Objectives: This study sought the views of sadhus in Nepal. Method: During the major Shiva festival at Pashupathinath temple complex in Kathmandu, Nepal, 200 sadhus were surveyed. Results: Most used cannabis daily, a quarter believed cannabis and its use to be legal in Nepal, and a further ten percent were unsure, about one third believed cannabis should be used by Hindus, but only fourteen believed Lord Shiva promoted its use. Those less educated and from the Naga sect were more likely to hold such views, and provide cannabis to devotees. Conclusions: Sadhus with evidence-based information about cannabis and its potential harms can play an important role in assisting to reduce harm and facilitate engagement in treatment.
\end{abstract}

Key words: Health Promotion, Mentally ill, Nepal

\section{INTRODUCTION}

Cannabis is found growing wild in most of Nepal. Historically, cannabis is believed to be the loved substance of Hindu God Shiva, and has been an integral part of Hindu practice and culture.1-7 Every year, in religious celebrations such as Shivaratri - a celebration in reverence of Lord Shiva, many people smoke cannabis and drink bhang (drink made from ground leaves and flowers from the female cannabis plant, spices and milk). The association of cannabis and Shiva has been described as 'benign' as it affords devotees the 'means of honouring the deity while more fully celebrating the festivals' and, for sadhus, 'union with the divinity by facilitating arduous physical and mental spiritual practice' $^{\prime 2}$

Some believe it to be almost mandatory to use cannabis to receive the blessings of gods and goddesses, and its use in specific festivals is regarded as similar to the Christian use of alcohol in some religious ceremonies. ${ }^{3-8}$ However, the association may not be as benign as suggested from a public health perspective, and differs from most Christian religious ceremonies where alcohol intoxication is not condoned. Other commentators share such a view: 'The [Hindu] scriptures have not encouraged recreational use, intoxication from, or abuse of the substance. The scriptures warn against the over-use of alcohol and other intoxicants and they teach against using any substances for intoxication. The fact that marijuana is sacred to Shiva does not mean that it is good for people to consume' ${ }^{7}$

In addition to its spiritual and religious use, cannabis also has various social and medical 
uses. In Nepal, people smoke cannabis at festivals and gatherings or when in mourning, and use it to relax, reduce anxiety and stress and to aid concentration. It is also used to treat illnesses in domestic animals, and, especially in Ayurvedic practice (Hindu traditional medicine of Vedic [Hindu scripture] tradition), people also use it to treat food poisoning, digestive problems, diarrhoea, rheumatism, gout, to reduce pain and the exhaustion of heavy manual work, to increase appetite and reduce insomnia, mixed in sweets to help children relax while their mother works in the fields, and to protect and heal illness related to evil spirits. $4,7,8,9$ Thus, Nepali culture has a close affinity with cannabis, and cannabis has long been an integral part of Nepalese society.

Prior to 1973, Kathmandu had been viewed as a 'hippie paradise'. There were numbers of government run hashish and 'marijuana' shops where people could buy and smoke it freely. Farmers produced enough high quality hashish that they would sell quickly for a good price, and live comfortably for the remainder of the year. ${ }^{10}$ However, in July 1973, the government of Nepal, apparently under pressure from the US, revoked all licences to cultivate, buy and sell cannabis, and in September 1976, the Narcotic Drugs (Control) Act 2033 made cannabis illegal. ${ }^{11}$ Hash shops and coffee houses were closed and many 'hippies' were put on trucks and deported to India. However, despite its illegality, cannabis continues to grow wild, is also cultivated in the south of Nepal, remains easily accessible throughout the country, and its use is essentially tolerated without sanction during festivals such as Shivaratri. ${ }^{3}$

While possibly benign enough for many, cannabis and its use appears to have some public health implications for Nepal, as in other countries. ${ }^{12-15}$ Researchers and commentators have drawn attention to increasing cannabis use among young people in Nepal, and its health and social impacts. There have, for example, been reports of young people in 'toxic states' in need of medical treatment, cannabis-induced psychoses and the precipitation of schizophrenia, and an association with depression. ${ }^{16}$ In addition, concerns have been raised by some Opioid Substitution Treatment (OST) services about the impact of cannabis on OST clients. ${ }^{17}$

\section{What is known about cannabis use in Nepal?}

Despite its ready availability and raised concerns about health impacts from its use, little is known about the use of cannabis among the general population, as available studies only report on those in drug treatment and unrepresentative samples such as medical students. The 2012 Ministry of Home Affairs survey estimated 91,534 'hard drug users' in Nepal, with $90.5 \%$ having reported cannabis use and $74.1 \%$ of respondents combined cannabis with 'tranquilizer' drugs. Cannabis was the most popular among the youngest group aged less than 15 years. ${ }^{18}$

A cross sectional study conducted among the medical students in Nepal showed that 18.5\% had used cannabis ${ }^{19}$, with greater use among those students living away from home. An earlier study of junior doctors in teaching institutes in Nepal found that $15 \%$ reported use of cannabis. ${ }^{20}$ This finding is similar to that of Khanal et al. ${ }^{21}$, for first and final year medical students from four medical colleges, which found a lifetime prevalence of cannabis use of $12.8 \%$.

Globally, cannabis is the most prevalent type of illicit substance used among OST clients with estimates of concurrent use ranging from $50 \%$ to $85 \% .22$ While there is no local data on the issue, treatment services in Nepal have concerns about the prevalence of cannabis use, its potential impact on the physical and mental health of clients, treatment compliance, adherence to program, impacts on medication efficacy, and overall social and economic functioning. A pilot survey at an NGO OST service in 2013, found that among the 20 exOST participants, many used cannabis while initiating OST, on OST and while withdrawing from OST. Participants reported using between 14 to 21 joints per week, and many believed that Lord Shiva and sadhus promoted its use. ${ }^{17}$

The aim of the study was to explore the use of cannabis among sadhus, as sadhus are popularly believed to suggest that Lord Shiva promoted the use of cannabis; a common rationalisation by clients of OST programs and the general community. 


\section{MATERIAL AND METHOD}

A cross sectional study of 200 sadhus at Pashupatinath Temple, Kathmandu during Shivaratri in February 2014. Pashupatinath, Nepal's oldest (400 AD) and most sacred Hindu shrine, is a major temple complex located in Kathmandu on the banks of the Bagmati River. It includes numerous cremation ghats, and is a World Heritage listed site, and the seat of the local deity - Lord Pashupatinath. Shivaratri at Pashupatinath attracts sadhus from all over Nepal and nearby Indian states, many of them migrating holy men and women. The survey instrument was developed from a preliminary qualitative survey of 15 sadhus at Pashupatinath in late 2013.23

The survey instrument comprised 32 items covering basic demographics, education, initiation to cannabis use, perceived benefits of early and current use, difficulties encountered with use of cannabis, beliefs about Lord Shiva and cannabis, provision of cannabis to devotees, whether certain people should avoid use of cannabis and the legality of cannabis in Nepal. Opportunities were provided for additional qualitative responses to be recorded.

Ethical approval was obtained from the Pashupathinath Area Development Trust and the Nepal Health Research Council. Interviews were conducted by the chief investigator and five research assistants trained by the chief investigator, over five days of the Shivaratri Festival in February 2014. Only two sadhus approached refused to participate, and those who did were provided with a small gift of food items and reimbursed around \$US 5. Date were analysed using SPSS package.

Procedure: The first author and research assistants attended the Shiva Ratri festival at Pashupathinath Temple for three days. Sadhus were approached at random in the sectors of the temple associated with the various sects residing there, the study was explained, and if informed consent was obtained, the survey was administered in a setting most comfortable to the individual sadhu. During the survey period, a video documentary was made by Saarathi Nepal. ${ }^{24}$

\section{RESULT}

The majority of the sadhus interviewed were male $(90.5 \%)$, with mean age of 51.8 years (range 18 to 85 ). The majority had never been married $(63.1 \%), 21.2 \%$ were married or cohabiting, with $28.2 \%$ having one or two children, and $37.4 \%$ with three or more. The sadhus came from various Hindu sects: Santanan/Fakir - 31.5\%, Naga - 27\%, Aghori $12 \%$, Baishnav - 9.5\%, and Pandit - 9\%.

A significant number (47.5\%) of sadhus had no formal education, with $20.5 \%$ were informally educated by gurus (Guru Kula), 19\% having completed primary and $10.5 \%$ secondary education, and only $2 \%$ further technical or diploma courses. While the majority were aware that cannabis was illegal in Nepal $(63.8 \%), 24.9 \%$ believed it was legal, and $10.3 \%$ were unsure.

Participants tended to underestimate how many sadhus used cannabis, with $23.2 \%$ believing it was less than $50 \%, 25.7 \%$ said $51-$ $70 \%$, and $51 \%$ said greater than $71 \%$. The vast majority $(90 \%)$ of participants reported current daily cannabis use. The mean age in initial cannabis use was 17.1 years (range 5 to 46 ).

Table 1: Reasons for initiation and current use of cannabis provided by sadhus at Pashupathinath $(\mathrm{N}=200)$

\begin{tabular}{|l|l|l|}
\hline Reason & First use \% & $\begin{array}{l}\text { Current use } \\
\text { \% }\end{array}$ \\
\hline Meditation & 54.9 & 80.0 \\
\hline Recreation & 41.6 & 17.1 \\
\hline Relaxation & 29.7 & 59.1 \\
\hline Fun & 28.3 & 7.9 \\
\hline Anger control & 26.4 & 30.5 \\
\hline Improve mood & 25.3 & 23.2 \\
\hline Aid digestion & 15.4 & 24.4 \\
\hline Aid concentration & 12.1 & 22.6 \\
\hline Control urges & 11.0 & 16.1 \\
\hline Control sex urge & 9.9 & 24.4 \\
\hline Protect from cold & 8.8 & 26.2 \\
\hline Get high & 7.7 & 9.1 \\
\hline Pain & 5.5 & 8.4 \\
\hline Improve appetite & 5.5 & 11.6 \\
\hline
\end{tabular}


Table 1 displays reported reasons for initial and current use of cannabis by the sadhus. Initiation tended to be mainly associated with meditation and recreation, and relaxation and fun, whereas current use was associated mainly with meditation and relaxation, and protection from cold, aiding digestion and concentration, and controlling control of sex urges.

Approximately one third (31.7\%) of participants believed Hindus should use cannabis for religious reasons, 20.7\% encouraged devotees to use cannabis, and $32 \%$ gave cannabis to devotees as prasad/buti (a religious gift) to consume or place in a medallion worn on a necklace of beads. Only $13.5 \%$ stated that Lord Shiva said cannabis should be used. About one quarter (23.3\%) believed some groups should not use cannabis, mainly children and non-sadhus, with few identifying harmful health, social and economic consequences of cannabis use. A small number of the Sadhus (15.6\%) reported that they had a problem with their use of cannabis and tried to reduce/quit at some stage.

Naga sadhus more frequently provided cannabis to devotees [ $\left.X^{2} 15.94, \mathrm{df} 6, \mathrm{p}=0.014\right]$, and believed that Lord Shiva endorsed its use $\left[x^{2} 22.54\right.$, df $\left.5, p=0.013\right]$. Naga sadhus and those less educated and those educated by 'gurus' were more likely to believe Hindus should use cannabis [Naga: $\chi^{2} 32.27$, df $6, p=$ $<0.000$; Guru Kala or no formal education: $\chi^{2}$ 46.63, df 5, $\mathrm{p}=<0.000]$.

\section{DISCUSSION}

Virtually all sadhus surveyed reported daily use of cannabis, and some provision of cannabis as a 'gift' to 'devotees'. The Naga sect, the less educated and those educated by gurus $(68 \%$ of sample) were more likely to provide cannabis to devotees, and believe that cannabis should be used by Hindus. However, only $13.5 \%$ states that Lord Shiva said cannabis should be used.

Current cannabis use by sadhus was mainly for religious and spiritual (meditation) purposes, for relaxation and to control urges.
Initial use was more for recreation and pleasure. There appears to be limited recognition of potential negative consequences of cannabis use, although about one quarter indicated that some people should not use cannabis, mainly children. While there tends to be a belief among some that sadhus may promote the use of cannabis ${ }^{2}$, the majority of sadhus surveyed $(68 \%)$ in this study did not endorse such a view, and some Hindu scholars actually caution that cannabis intoxication is undesirable. ${ }^{7}$

However, Shivaratri is characterized by open use of cannabis, flaunting of the law, and excessive consumption, condoned and even encouraged by many Sadhus. This provides positive messages about cannabis and its use, and ignores or minimizes any potential health and social risks. Observation by the researchers and a video documentary ${ }^{24}$ made during the festival clearly indicated that it cannot be assumed that all cannabis consumption during Shivaratri is for 'spiritual and religious' purposes.

Morningstar has stated, 'Hindu beliefs about appropriate use of cannabis illustrate the capacity of cultural systems to order and direct the course of complex phenomenal events. Cannabis manifests diverse and contradictory effects. These depend not only on dose, frequency and route of administration, but also on subjective and cultural contexts .... The Hindu cultural system ... accommodates the ambiguities of cannabis through its own complex nature. ${ }^{5}$ This cultural system appears to have great potential to inform followers of potential negative physical and mental health and social impacts of cannabis use; sadhus are central to this.

Sadhus can assist public health and treatment responses for those with cannabis useassociated or exacerbated conditions, but many appear to need information and education as to possible negative health, social and economic impacts of frequent and heavy cannabis use. They are influencers of opinion and behavior, and they may be able to enhance treatment interventions, especially with vulnerable individuals and communities with complex presentations, including mental health concerns, hepatitis C (HCV), HIV and for those on OST. Sadhus can probably assist 
those attempting OST and other drug treatment to better manage the 'frustrations' of withdrawal and the treatment process ${ }^{25}$, without heavy use of a substance that may be a significant factor in relapse and early exit from effective treatments such as OST.

However, the evidence is not clear as to the role of use of cannabis by people in OST ${ }^{26}$ and for those with $\mathrm{HCV} .{ }^{27-29}$ A recent study examined cannabis use among opiate-dependent individuals during methadone maintenance therapy (MMT) induction, and found that while cannabis use was high during methadone induction, it declined significantly following stabilization and with treatment compliance. ${ }^{26}$ The authors noted the possible role of cannabis use easing induction to MMT. However, an Indian study ${ }^{31}$ on cannabis use among individuals on OST, identified issues such as inadequate control of opioid withdrawals, cerebrovascular conditions, interactions with OST medications, treatment adherence, and relapse as requiring investigation.

Regular cannabis use in persons with chronic $\mathrm{HCV}$ has been reported to be associated with increase fibrosis, steatosis and a reduction the rate of viral eradication, with patients being advised to cease regular use of cannabis. $28,29,32$ However, the World Health Organization, (WHO) has been more cautious noting 'paucity of data' and 'conflicting reports on any association with liver disease'. ${ }^{30}$

Clearly, further research is required to explore the role of cannabis use among people in drug treatment, especially OST. Such research could focus on: cannabis use and induction to and withdrawal from OST; cannabis use plasma methadone concentrations; the impact of heavy cannabis use on initiation and exacerbation of serious mental health disorders for those on OST; possible roles for sadhus in assisting those in OST and other treatments to consider their use of cannabis, and better manage the many 'frustrations' inherent in addressing concurrent potentially problematic cannabis use including those in the spiritual domain.

A limitation of this study is that due to the nature of the Shivaratri, many sadhus residing at Pashupathinath temple were not permanent temple residents. While this may have had an impact on the results, it provided a broad cross-section of sadhus for the study. In addition, the results of the study may not be generalizable to all sadhus in Nepal, as Shivaratri mostly attracts those devoted to Lord Shiva.

\section{CONCLUSION}

Most sadhus surveyed used cannabis daily, a quarter believed cannabis and its use to be legal in Nepal, a further ten percent were unsure, and about one third believed cannabis should be used by Hindus. However, only $14 \%$ believed Lord Shiva promoted its use. Those less educated and from the Naga sect were more likely to hold such views, and provide cannabis to devotees.

Sadhus with evidence-based information on cannabis and its potential harms can play an important role in the recovery of people who use drugs, via attention to spiritual issues, and in clarifying misinformed beliefs about lord Shiva and his relationship with cannabis. Such involvement could be associated with greater engagement with, and retention on OST and other programs, and reduced mental health concerns. For those on OST, they may assist participants gain greater benefit from their treatment by considering their use of cannabis, not invoking Lord Shiva as an excuse for continued use, and improve their mental health, to manage the 'frustrations' inherent in recovery from substance dependence.

\section{ACKNOWLEDGEMENT}

The authors would like to thank the sadhus who willingly agreed to be interviewed during Shivaratri at Pashupathinath Temple, Kathmandu , the Pashupathinath Area Development Trust, and the research assistants: Ajay Bhatta, Prashant Baral, Rakesh Ayer, Sunil Poudel, Bibek Pathak, and Mamata Ghimre.

\section{DECLARATION OF INTEREST}

The authors report no conflicts of interest. The authors alone are responsible for the content and writing of the article.

\section{REFERENCE}

1. Aldrich, I. Tantric cannabis use in India. Journal of Psychedelic Drug. 1977; 9 (3): 227-233. 
2.Godlaski, T. Shiva, Lord of Bhang. Substance Use and Misuse 2012; 47(10): 1067-1072.

3. Jha, C., Plummer, D. Culture, identity and the embodiment of illicit drug use in Nepal. Mental Health and Substance Use 2014; 7(1): 5-18.

4. Kuddus, M., Ginawi, I., Al-Hazimi, A. Cannabis Sativa: an ancient wild edible plant of India. Emirates Journal of Food and Agriculture 2013; 25 (10): 736-745.

5. Morningstar, P. Thandi and Chilam: Traditional Hindu beliefs about the proper use of cannabis. Journal of Psychoactive Drugs 1985; 17(3): 141-165.

6. Shastri, J. (Ed.) Shiv Puran. Delhi: Motilala Banarsidass Publisher; 2008.

7. Shri Shukla-Bhadra Soma Peetham. Ayurvedic View of Marijuana; 2013. Website: Retrieved December 10, 2014. http://www.somamatha.org/ayurvedic-view-ofmarijuana.html

8. Touw, M. The religious and medicinal uses of cannabis in China, India, and Tibet. Journal of Psychoactive Drugs 1981; 13(1): 23-34.

9. Robertson, J., Miller, P., Anderson, R. Cannabis Use in the Community. British Journal of General Practice 1996; 46: 671 -674.

10. Pietri, J. The King of Nepal: Life before the drug wars. Walterville: TrineDaly; 2010.

11. Government of Nepal. Narcotic Drugs (Control) Act 2033. Nepal; 1976

12. Hall, W. The adverse health effects of cannabis use: what are they and what are their implications. International Journal of Drug Policy 2009; 20: 258466.

13. Hall, W., Pecula, R. Cannabis use and dependence: Public health and public policy. Cambridge: Cambridge University Press; 2003.

14. Smit, F., Bolier, L., Cuijpers, P. Cannabis use and the risk of later schizophrenia: a review. Addiction 2004; 99: 425-430.

15. United Nations Office on Crime and Drugs (UNODC). Cannabis: a short review. Vienna: UNODC; 2012.

16. Pradhan, S., Sharma, S., Shrestha, M., Shrestha, S. A study of depression among patients of substance use disorder. Journal of Kathmandu Medical College 2012; 1(2,2): 96-99.

17. Lama, K., Shrestha, R., Howard, J. Acharya, S. Cannabis use among ex-OST clients. Unpublished, Saarathi Nepal; 2013.

18. Ministry of Home Affairs. Survey Report on Current Hard Drug Users in Nepal - 2069. Nepal; 2012.

19. Budhathoki, N., Shrestha, M., Acharya N, Manandhar A. Substance Use among Third year Medical Students of Nepal. Journal of Nepal Health Research Council 2010; 8(16): 15-18.

20. Shyangwa, P., Joshi, D., Lal, R. Alcohol and Other Substance Use/ Abuse Among Junior Doctors and Medical Students in Teaching Institute. Journal of Nepal Medical Association 2007; 46 (167): $126-129$.
21. Khanal, P., Ghimire, R., Gautam, B., Dhungana, S., Parajuli, P, Jaiswal, A., Khanal, B. Substance use among medical students in Kathmandu Valley. Journal of Nepal Medical Association 2010; 49(180): 267-272.

22. United Nations Office on Crime and Drugs (UNODC). (Review of world cannabis situation. Bulletin on Narcotics: LVIII, (1 and 2). Vienna: UNODC; 2006.

23. Acharya, S., Howard, J. Cannabis use among sadhus at Pashpathinath Temple, Kathmandu, Nepal. Unpublished; 2013.

24. Saarathi Nepal. Youth, Sadhus and Ganja. Video documentary made during Shivaratri, Pashupathinath Temple, Kathmandu, Nepal, February 2014. Available: https:/ / www.youtube.com/watch?v=2Uq8Id4eN5 Q\&list=UUECis0vYBKV8735EcR7840Q\&index=1

25. Jha, C., Plummer, D. Unpacking drug detoxification in Nepal: in-depth interviews with participants to identify reasons for success and failure. International Journal of Psychosocial Rehabilitation 2012; 16 (2): 50-61.

26. Scavone, J., Sterling, R., Weinstein, S., Van Bockstaele, E. Impact on cannabis use during stabilization on Methadone Maintenance, American Journal on Addiction 2013; 22: 344-351.

27. Brunet, L., Moodie, E., Rollet, K., Cooper, C., Walmsley, S., Potter, M., Klein, M., and others. Marijuana smoking does not accelerate progression of liver disease - Hepatitis Coinfection: a longitudinal analysis. Clinical Infectious Diseases 2013; 57(5): 663-670.

28. Ishida, J., Peters, M., Jin, C., Louie, K., Tan, V., Bacchetti, P., Therrault, N. Influence of cannabis use on severity of Hepatitis C disease. Clinical Gastroenterology and Hepatology 2008; 6: 69-75.

29. Hézode, C., Roudot-Thoraval, F., Nguyen, S., Grenard, P., Julien, B., Zafrani, E., Pawlostky, J., Dhumeaux, D., Lotersztajn, S., Mallat, A. Daily cannabis smoking as a risk factor for progression of fibrosis in chronic Hepatitis C. Hepatology 2005; 42: 63-71.

30. World Health Organization (WHO). Guidelines for the screening, care and treatment of persons with hepatitis C infection. Geneva: WHO; 2014.

31. Balhara, Y., Raka, J. Cannabis use among opioiddependent individuals on opioid substitution therapy. Journal of Pharmacology and Pharmacotherapeutics 2014; 5(3): 203-205.

32. Hézode, C., Zafrani, E., Roudot-Thoraval, F., Costentin, C., Hessami, A., Bouvier-Alias, M., Medkour, F., Pawlostky, J., Lotersztajn, S., Mallat, A. Daily cannabis use: a novel risk factor of steatosis severity in patients with Chronic Hepatitis C. Gastroenterology 2008; 134: 432-439. 